\title{
Combining phytate treatment and nanocellulose stabilization for mitigating iron gall ink damage in historic papers
}

L. Völkel ${ }^{1,3}$, T. Prohaska ${ }^{2}$ and A. Potthast ${ }^{3 *}$ (1)

\begin{abstract}
Because of its acidic and oxidative nature, iron gall ink promotes the endogenous degradation of paper manuscripts. Mechanical damage in areas of concentrated ink application or along mechanically stressed edges or folds results in problems during storage and handling. So far, such strongly degraded areas have usually been stabilized locally with thin Japanese paper and adhesives. A new and innovative material — nanocellulose —is being evaluated as a stabilizer for manuscripts that have been degraded by iron gall ink. The aim of this study is to integrate the nanocellulose application into a multi-stage calcium phytate/calcium hydrogencarbonate treatment to combine deacidification and stabilization, thus avoiding an additional stabilization and drying step. Two different types of fibrillated nanocelluloses were applied on manuscripts damaged by iron gall inks in different treatment steps. The newly formed, interlinked network of nanocellulose and paper was characterised before and after accelerated degradation in closed vials. The effects on the paper cellulose were studied by size exclusion chromatography and light scattering with carbonyl group profiling to follow cellulose hydrolysis and oxidation pathways. In addition, the migration behavior of iron ions was examined by laser ablation coupled with metal analysis (ICP-MS). This paper discusses the applicability and stability of nanocellulose on paper damaged by iron gall ink with regard to its long-term performance. Advantages and limitations are covered in detail.
\end{abstract}

Keywords: Iron gall ink, Calcium phytate/calcium hydrogencarbonate treatment, Nanocellulose/nanofibrillated cellulose, Chemical stabilization, Mechanical stabilization, Gel Permeation Chromatography, Laser Ablation-ICP-MS

\section{Introduction}

Ink corrosion-a complex degradation process of cellulose in paper-is caused by iron gall ink. Such damage is a frequent phenomenon in the case of manuscripts or drawings from early Middle Age to the 20th century [1]. Iron gall ink was one of the most common writing media for centuries. It is produced from an iron salt, mostly iron (II) sulphate, and a tanning agent, e.g., gall apples from which gallotannins could be extracted. Those

\footnotetext{
*Correspondence: antje.potthast@boku.ac.at

${ }^{3}$ Department of Chemistry, Institute of Chemistry of Renewables

and Institute of Wood Technology and Renewable Materials, University of Natural Resources and Life Sciences (BOKU), Konrad-Lorenz-Strasse 24 3430 Tulln, Austria

Full list of author information is available at the end of the article
}

components were mixed with water, and a binder (e.g. gum Arabic) was added to adjust the viscosity and to prevent precipitation of the iron-gallus complex. Different additives were used to modify the characteristics of the inks, such as color, gloss, intensity or stability [2]. The ink was always prepared individually according to different local recipes so that many formulations and high compositional variability resulted, in particular with regard to different proportions of iron (II) sulphate gallic acid and additives. The chemistry of the interaction of iron(II) sulphate and tannic and the iron gall inks formed from these compounds is rather very complex [3-5].

Iron(II) sulphate and acid, which are mostly present in excess, are responsible for the degradation of
Springer Open

(c) The Author(s) 2020. This article is licensed under a Creative Commons Attribution 4.0 International License, which permits use, sharing, adaptation, distribution and reproduction in any medium or format, as long as you give appropriate credit to the original author(s) and the source, provide a link to the Creative Commons licence, and indicate if changes were made. The images or other third party material in this article are included in the article's Creative Commons licence, unless indicated otherwise in a credit line to the material. If material is not included in the article's Creative Commons licence and your intended use is not permitted by statutory regulation or exceeds the permitted use, you will need to obtain permission directly from the copyright holder. To view a copy of this licence, visit http://creativeco mmons.org/licenses/by/4.0/. The Creative Commons Public Domain Dedication waiver (http://creativecommons.org/publicdomain/ zero/1.0/) applies to the data made available in this article, unless otherwise stated in a credit line to the data. 
cellulose. They act as catalysts for two essential, largely simultaneous processes:

- The high acid content of the inks leads to the hydrolytic cleavage of the cellulose,

- The free iron(II/III) catalyses the oxidative degradation of cellulose according to radical (homolytic) pathways.

In literature, the significance and contribution of both processes have been discussed extensively. Nevertheless, it is not easy to describe the overall system, with the mechanisms that contribute to natural aging not yet being fully known, and no generally accepted kinetic models existing [6,7].

Various studies with model papers and historical sample materials showed synergistic effects between hydrolysis and oxidation and demonstrated those processes to be interdependent. The two processes depend on the type and the composition of the iron gall ink [8-13]. Furthermore, the degradation processes are influenced by other endogenous and exogenous factors $[11,12]$. Current results indicate that hydrolysis is likely to be the primary contributor to cellulose degradation, and that oxidation becomes more important with decreasing moisture content [6].

The damage at the molecular level (degradation/ oxidation of cellulose chains) translates into typical changes of mechanical properties of the paper, such as loss of mechanical strength and increased brittleness.

Reissland and Hofenk de Graaff [14] classified four conditions according to the type of damage caused by ink corrosion (cf. Table 1). This enables restorers to assess the extent of the damage and effectively evaluate treatment measures.

Effective countermeasures to ink corrosion require two processes: a chemical treatment to neutralize free acids (deacidification), and the inactivation of any free transition metal ions (complexation of iron(II) and iron(III) ions). Different protocols are available in literature [15-18]. We concentrated on the phytate treatment as a proven system to counteract hydrolysis and oxidation in iron gall ink papers. Upon the combined calcium phytate/calcium hydrogencarbonate treatment developed by Neevel [10], papers are deacidified by the $\mathrm{Ca}\left(\mathrm{HCO}_{3}\right)_{2}$, and further oxidation by free iron ions is prevented by complexation with phytate. The effectiveness of this treatment has been demonstrated, and it has become well accepted among restorers $[8,9,19$, 20]. Today it is available as a standardised protocol for the treatment of damaged manuscripts [21, 22].

Chemical treatment, however, is only one aspect of a process to effectively preserve manuscripts damaged by ink corrosion. Ink corrosion is often accompanied by severe mechanical damage (cracks, fractures) which makes additional physical stabilization necessary [23, 24]. Hence, local support of damaged paper areas with Japanese papers, adhesives or remoistening tissues is usually applied, depending on the degree of damage [25-28]. In the case of severely impaired manuscripts, several authors suggested lining the documents with Japanese paper directly after aqueous or chemical treatment [18, $23,24,29]$. In the present study, we test whether stabilization with nanofibrillated cellulose-one type of nanocellulose-can be implemented directly into the phytate treatment sequence.

Nanocelluloses form strong, transparent, fibrillar networks on-and partly with-the paper matrix, and they show quite favourable aging behavior [30, 31]. Hence, their material properties are very interesting to paper conservators. So far, nanocellulose has been applied as dry film with adhesives $[32,33]$ or as aqueous suspension [34-36]. With regard to the latter, we have recently developed a protocol to stabilize damaged paper without using additional adhesives [36]. In this work, the stabilizing effect of two types of nanofibrillated celluloses is studied, answering the question of whether it can be safely combined with a phytate/calcium hydrogencarbonate protocol and how it might affect the final stabilization of the material.

\section{Materials and methods \\ Types of nanofibrillated cellulose}

Two commercially available fibrillated nanocelluloses (CNF) were tested. Fibrillated nanocellulose A (Exilva F-01, CNF A) was purchased from Borregaard AS as a white aqueous suspension with a solids content of $1.9 \%$ in $\mathrm{H}_{2} \mathrm{O}$ and a $\mathrm{pH}$ of 6.6. The cellulose material had a molecular weight of $310.6 \mathrm{~kg} / \mathrm{mol}$ (DP 1916) and a whiteness of

Table 1 Classification of iron gall ink damages according to Reissland and Hofenk de Graaff (2000)

\begin{tabular}{ll}
\hline Good condition (condition rating 1) & No or light brown discolouration, no mechanical damages, normal careful handling \\
Fair condition (condition rating 2) & Dark brown discolouration, ink penetration, no mechanical damages, special care in handling necessary \\
Poor condition (condition rating 3) & ink penetration, mechanical damage (cracks), handling by a knowledgeable person with support still possible \\
Bad condition (condition rating 4) & ink penetration, severe substance loss, handling only with the risk of loss (restrict handling, with support)
\end{tabular}


88.7\% ISO. Suspensions were diluted to a solids content of $1 \%$ before usage.

Nanofibrillated cellulose B (CNF B) was provided by SAPPI, Belgium, as a white aqueous suspension with a solids content of $1 \%$ in $\mathrm{H}_{2} \mathrm{O}$ and a $\mathrm{pH}$ of 7.2. The molecular weight was $285.6 \mathrm{~kg} / \mathrm{mol}$ (DP 1761) and the degree of whiteness $89.5 \%$ ISO. This material was used as is $(1 \%$ aqueous suspension).

\section{Chemicals}

Phytic acid (myo-inositol hexakis (dihydrogen phosphate)), as $40-50 \mathrm{wt} \%$ aqueous solution, calcium carbonate, ammonium hydroxide solution (1.5\%), ethanol (96\%) and 2-propanol were purchased from Sigma-Aldrich (Schnelldorf, Germany). Photo gelatine, type Restoration 1 (from Gelita), was obtained from GMW Gabi Kleindorfer, Germany.

The treatment solutions were used in the following concentrations [cf. 21]:

- 40\% 2-propanol-water mixture and 80\%, 50\%, 30\% ethanol-water mixture.

- $1.75 \mathrm{mM}$ calcium phytate solution.

- $0.018 \mathrm{M}$ calcium hydrogencarbonate solution.

$-0.2 \%$ solution of gelatine.

\section{Model paper}

\section{Fair condition}

Rag papers from a collection of handwritten sermons from the years 1839 and 1840 were used as sample materials. Each 3-4 folded double sheets form a unit and are bound with a cover to a booklet. Cover paper and text sheets differ, but the text paper of a booklet is usually of the same type. One double sheet was always used for one pair of samples (unaged and aged) which received the same treatment. The iron gall ink-damaged paper was in fair condition (condition rating 2). This means that the ink penetrated to the reverse side and halos had formed, but no mechanical damage was visible [14].

\section{Poor and bad condition}

Single sheets of either poor or bad condition (condition ratings 3 and 4) were obtained by accelerated degradation with hydrochloric acid in the gas phase. The use of $\mathrm{HCl}$ to cause faster mechanical damage in the ink and paper area was derived from a study by Kontturi et al. [37] describing the influence of gaseous $\mathrm{HCl}$ on cellulose. After aging, the samples showed varying degrees of mechanical damage, and they were very fragile and browned as desired.

\section{Application of nanofibrillated cellulose and calcium phytate/calcium hydrogencarbonate}

Each treatment procedure involved two pairs of samples. Since two types of fibrillated nanocellulose were used, there was one pair of A-samples and one pair of B-samples per variant.

As reference material, two pairs of samples were treated according to the regular procedure established by Huhsmann and Hähner [21] (referred to as the treated references) and three pairs of samples were not treated (the untreated references).

In the following, the standard treatment procedure of Huhsmann and Hähner [21] and the concentration given therein are considered as starting points for any subsequent variation. The CNF variants (see variant 1-5) were applied on both sides with a brush on a vacuum panel (mobile vacuum panel RSP1 with plastic sintered plates (hydrophilic, PE), GMW, Germany). After the treatment, the samples were placed between nonwoven Holytex sheets.

\section{Variant 1}

For $50 \mathrm{~mL}$ of treatment solution, calcium carbonate $(22 \mathrm{mg}$ ) and phytic acid (115 mg) were dissolved in $25 \mathrm{~mL}$ of deionized water. $25 \mathrm{~mL}$ of a $2 \%$ CNF suspension was added and the suspension stirred on the magnetic stirrer for approx. 30 min. For a solid concentration of $2 \%$, the original CNF suspension was concentrated by centrifugation (5000 RPM/30 min).

\section{Variant 2}

Calcium carbonate $(55 \mathrm{mg})$ was dissolved in $25 \mathrm{~mL}$ deionized water under flushing with $\mathrm{CO}_{2}$. The solution was mixed 1:1 (v/v) with a $2 \%$ CNF suspension, shaken, and stirred for $30 \mathrm{~min}$. For a solids concentration of $2 \%$, the original CNF suspension was concentrated by centrifugation (5000 RPM/30 min).

\section{Variant 3}

Gelatine $(100 \mathrm{mg})$ was added to $50 \mathrm{~mL}$ of $1 \%$ CNF suspension. The suspension was stirred on a magnetic stirrer at $750 \mathrm{rpm}$ and heating. The temperature of the mixture was controlled to avoid values above $60{ }^{\circ} \mathrm{C}$ (protein denaturation).

\section{Variants 4 and 5}

The two nanofibrillated celluloses were applied each as a $1 \%$ CNF suspension.

\section{Accelerated degradation}

To check the effect of each treatment on the longterm stability of the treated papers, half of the samples 
(fair condition) were artificially aged in closed vessels according to ASTM standard D6819-02e3 [38, 39]. The samples were preconditioned in $50 \mathrm{~mL}$ Schott bottles at $25{ }^{\circ} \mathrm{C} \pm 2{ }^{\circ} \mathrm{C}$ and $75 \% \mathrm{rH} \pm 2 \%$ in a glove box for $48 \mathrm{~h}$. To assure equal conditions for all samples, the bottles were then closed with a torque wrench and left airtight at $80{ }^{\circ} \mathrm{C}$ for 10 days $(240 \mathrm{~h})$.

Samples of poor and bad condition were obtained as follows:

Eight samples of fair condition were preconditioned in $50 \mathrm{~mL}$ Schott bottles at $25{ }^{\circ} \mathrm{C} \pm 2{ }^{\circ} \mathrm{C}$ and $75 \% \mathrm{rH} \pm 2 \%$ in a glove box for $140 \mathrm{~h}$. To create mechanical damage more quickly in the area with ink, $90 \mu \mathrm{l}$ of $0.1 \mathrm{M} \mathrm{HCl}$ was added to pieces of Whatman filter paper No.1. One piece of that $\mathrm{HCl}$-impregnated Whatman was added to the aging vials which leads to the desired increased hydrolytic damage to form samples of poor condition. Two pieces of impregnated Whatman filter paper were used to achieve samples of bad condition. The $\mathrm{HCl}$-impregnated papers had no direct contact with the rag paper to be aged, but released gaseous $\mathrm{HCl}$ as the actual degrading agent.

The bottles were closed with a torque wrench and placed in an oven (UFB 500, Memmert, Germany) at $80{ }^{\circ} \mathrm{C}$ for 10 days $(240 \mathrm{~h}$ ). After 10 days of aging, the $\mathrm{HCl}-$ impregnated papers were replaced by new ones containing $180 \mu \mathrm{l} \mathrm{0.1} \mathrm{M} \mathrm{HCl}$. Aging was continued at $90{ }^{\circ} \mathrm{C}$ for 5 days (120 h).

\section{CIELab measurement}

Color measurements for the range of 400-700 nm were performed with a spectrophotometer PCE-CSM 8 (PCE Instruments, Germany), using the device-independent CIELAB color space according to the EU standard EN ISO 11664-4 [40]. This method uses four parameters to describe the position of a specific color within the CIELAB color space: brightness $L^{*}$ with values between zero and 100, gradient $\mathrm{a}^{*}$ varying from green to red $\left(-50 \leq \mathrm{a}^{*} \leq+50\right)$, gradient $\mathrm{b}^{*}$ varying from blue to yellow $\left(-50 \leq \mathrm{b}^{*} \leq+50\right)$, and the Euclidean distance $\Delta \mathrm{E}$ which represents the average color change. It is calculated from $\Delta \mathrm{L}^{*}, \Delta \mathrm{a}^{*}$ and $\Delta \mathrm{b} *$ as follows:

$$
\begin{aligned}
& \Delta \mathrm{E}=\sqrt{\left(\Delta \mathrm{L}^{*}\right)^{2}+\left(\Delta \mathrm{a}^{*}\right)^{2}+\left(\Delta \mathrm{b}^{*}\right)^{2}} \\
& \Delta \mathrm{L} *=\left|\mathrm{L}_{2}^{*}-\mathrm{L}_{1}^{*}\right| ; \Delta \mathrm{a}^{*}=\left|\mathrm{a}_{2}^{*}-\mathrm{a}_{1}^{*}\right| ; \Delta \mathrm{b}^{*}=\left|\mathrm{b}_{2}^{*}-\mathrm{b}_{1}^{*}\right|
\end{aligned}
$$

The three components $\mathrm{L}^{*}, \mathrm{a}^{*}$ and $\mathrm{b}^{*}$ were recorded for six spots per sample. When calculating the difference values and the $\Delta \mathrm{E}$ value, the unaged sample was related to the aged sample. The six individual $\Delta \mathrm{E}$ values determined were averaged to obtain a representative $\Delta E$ value per sample.

\section{Contact angle measurement}

The contact angle measurements were performed with the Drop Shape Analyzer with camera system and the Advance software from Krüss (Germany). The sessile drop method was used. Drops of a volume of $0.2 \mu$ l were placed on the paper surface. Deionized water was used as measuring liquid. Four surface areas per sample were analysed either on a writing line (ink) or between the text lines (paper). For each area at least 5 adjacent measuring spots were evaluated. The first five measured values of each spot were checked for reliability. Afterwards, the mean value was calculated from the first three values of all five measuring points.

\section{Microscopy-SEM-EDX}

The surfaces of selected samples after treatment were examined by a scanning electron microscope FEI Quanta FEG 250 (Thermo Scientific). The paper surfaces were not coated.

\section{Laser ablation inductively coupled plasma mass spectrometry (LA-ICP-MS)}

The analysis of the migration of iron ions was performed using laser ablation inductively coupled plasma mass spectrometry (LA-ICP-MS). Laser ablation was accomplished by coupling a New Wave Research Nd:YAG $213 \mathrm{~nm}$ nano second laser ablation system (ESI, Bozeman, US) with an Agilent 8800 triple quadrupole ICPMS (Agilent, Santa Clara, US). Line scans using a $40 \mu \mathrm{m}$ spot size and a scan speed of $30 \mu \mathrm{m} / \mathrm{s}$ were performed on unaged and aged samples. Each data point represents an integral signal of $16 \mu \mathrm{m}$ in lateral (direction of the line) and $40 \mu \mathrm{m}$ in vertical (thickness of the line) direction.

Prior to each measurement, a gas blank was measured for $40 \mathrm{~s}$. The average value was used for blank correction of the subsequent laser ablation analysis of the paper samples. The limit of detection (LOD) was calculated as 10 times the standard deviation of the gas blank. Iron (Fe) was analysed as the ${ }^{57} \mathrm{Fe}$ signal, calculated relative to ${ }^{13} \mathrm{C}$ in order to normalize to the same relative ablated volume. An increase of the ${ }^{57} \mathrm{Fe}$ signal was interpreted as significant if the signal was higher than the background signal (measured at areas without ink) and 10 times the standard deviation of the background signal.

\section{SEC measurement and fluorescence labelling of carbonyl groups}

The samples were analysed for carbonyl group profiles according to the Carbazole-9-Carbonyl-Oxy-Amine (CCOA) method based on Röhrling et al. and Potthast et al. [41-43]. In addition, number of chain scissions (NCS), as a parameter reflecting cellulose degradation, 
was estimated according to Potthast and Ahn [44]. The calculation is based on the degree of polymerization before (DPo) and after (DP) accelerated aging, using the following equation:

$$
N C S=\frac{D P_{0}}{D P}-1
$$

DPo and DP are based on the weight-average molar mass obtained as an absolute value from SEC-MALLS. The relative standard deviation for carbonyl groups determination and molecular weight $(\mathrm{Mw})$ was below 5\% each.

\section{Results and discussion}

Various treatment procedures were tested, with the structure of the treatment sequences, in the following referred to as "variants", being shown in Fig. 1. The influence of these sequences and the order of their individual steps on the degradation behavior of the sample material, the effectiveness of the overall treatment and the

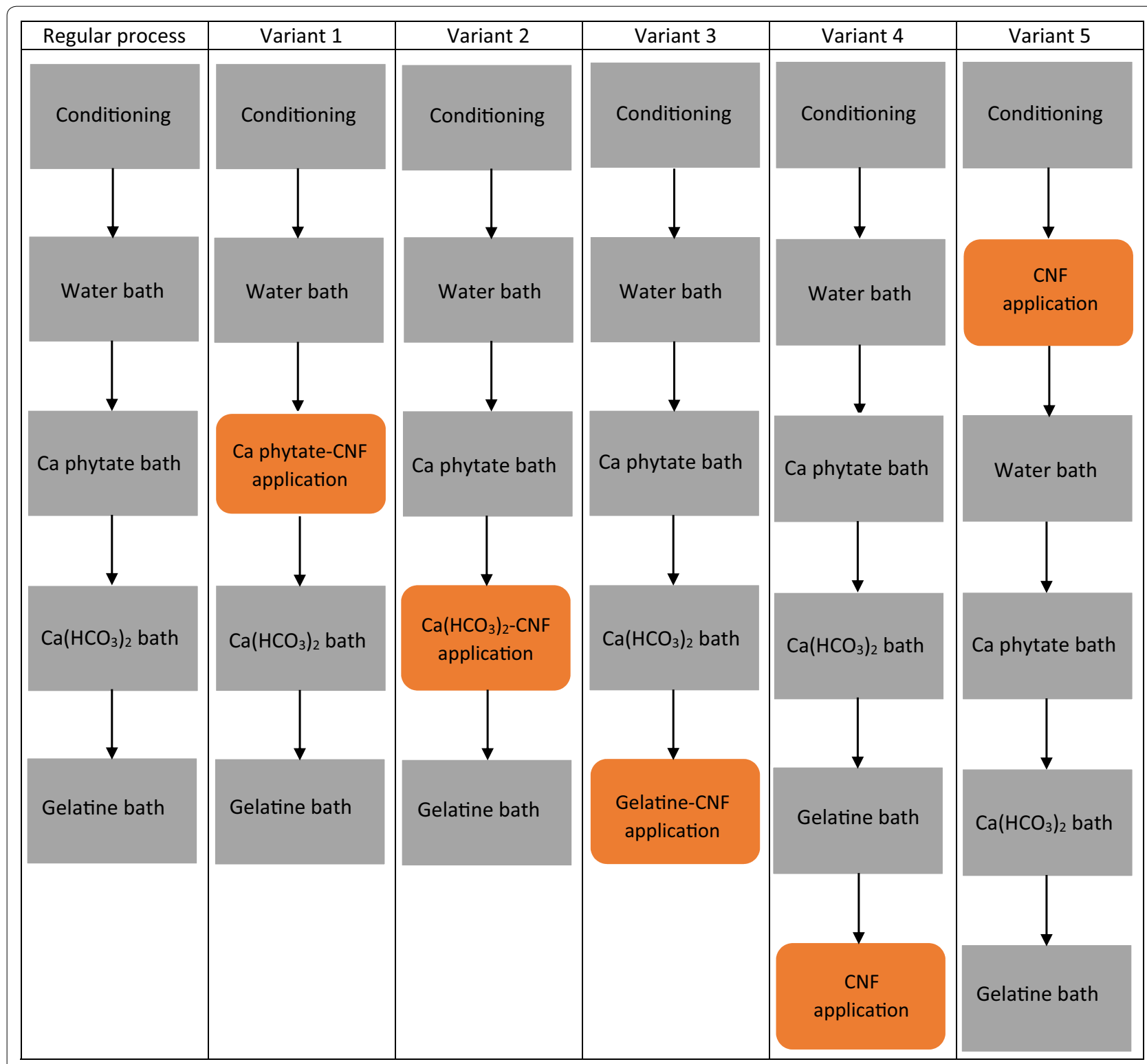

Fig. 1 Overview of the different treatment variants. The application of CNF was integrated at various stages of the calcium phytate/calcium hydrogencarbonate treatment. CNF was applied either as an additive to treatment solutions or in a separate, individual treatment step 
applicability to higher damage categories (poor and bad conditions) are discussed in the following.

\section{Treatment variants}

All variants that were developed and tested in the study could also be implemented in conservational practice. The addition of phytate or gelatine to the CNF suspension did not change the properties of the suspension in the application. The suspensions were stable and well applicable.

A common advantage of the different procedures is that chemical and mechanical stabilization, conventionally being separate treatments, are combined in one process. Other advantages and disadvantages in terms of treatment, application and results are summarized in Table 2, with the differences being based on the untreated references and the references treated according to the standard protocol [21].

\section{Practical aspects}

To test the practical applicability of the treatment variants on more severely damaged manuscripts, objects of poor and bad condition were treated by variants 2 , 4 and 5 . The results were evaluated optically and haptically. The occurrence of damage caused by the treatment itself and thus the gentlest possible implementation of the treatment was used as evaluation criteria.

Variants 2, 4 and 5 proved to be fully applicable to manuscripts of poor condition. The handling of the samples was risk-free and mechanically damaged areas were stabilized without subsequent damage or losses. The changes in the process of calcium phytate/calcium hydrogencarbonate treatment due to the implementation of the CNF application had no negative effect on the integrity of the manuscripts.

Samples of bad condition, which can normally only be handled with the risk of material loss, could be chemically and mechanically gently stabilized, without further damage or loss, especially with variant 5 (cf. Fig. 2), i.e., the "early" CNF application. By depositing the CNF prior to various treatment baths, fractures, cracks and imperfections were closed and sealed with a nanocellulose fibre network. The samples became manageable and the risk of further damage was thus minimized. By rinsing the samples in the baths on the wire, uneven coverage of CNF on the paper matrix was avoided. Displacements in heavily damaged papers were not observed. After rinsing, chemical treatment and re-sizing, the applied CNF was still present. Interestingly, the initially applied nanofibrillated cellulose was not washed away, but survived the later treatment steps. Thus, it was not necessary to repeat the application of fibrillated nanocellulose. Instead, the samples were transferred immediately to the dry stack.

The strong blurring of iron-gall ink visible in the samples is not the result of the new treatment with CNFs, see also the other samples provided in the supplement, e.g. Additional file 1: Figure S1. It was already present before, being caused by the accelerated degradation needed to induce the drastic damage typical of poor and bad condition and by the uneven conditioning due to the rolled state during accelerated degradation (cf. Fig. 2).

The damaged papers (gaseous $\mathrm{HCl}$ ) were not easy to handle. The paper was strongly browned and occurred to be very weak. During treatment, the samples had to be carefully manipulated. Especially when unrolling after conditioning and transferring from one fleece sandwich to another, it was necessary to exercise extreme caution. The vacuum table was an extremely helpful tool in making those transfers.

\section{Visual and haptic properties}

Visually, the treated samples showed almost no change for all the variants and CNF applications tested (cf. Fig. 3). Treatment with CNF generated a nicely stabilizing

Table 2 Advantages and disadvantages of the different treatment variants

\begin{tabular}{|c|c|c|}
\hline & Advantages & Disadvantages \\
\hline Variant 1 & Shorter treatment time & $\begin{array}{l}\text { Only a small amount of complexing agent is applied Complexing agents may } \\
\text { remain in the fibre network/on the sample }\end{array}$ \\
\hline Variant 2 & $\begin{array}{l}\text { An alkaline reserve may be deposited within the CNF layer } \\
\text { Shorter treatment time }\end{array}$ & $\begin{array}{l}\text { Only a small amount of calcium hydrogencarbonate solution is } \\
\text { applied } \longrightarrow \text { sufficient deacidification? }\end{array}$ \\
\hline Variant 3 & Only minor changes compared to the standard treatment & $\begin{array}{l}\text { CNF and gelatine combine to form a surface layer which may get sticky at } \\
\text { increased humidity }\end{array}$ \\
\hline Variant 4 & $\begin{array}{l}\text { Standard treatment is applied } \\
\text { Final mechanical stabilization before drying }\end{array}$ & \\
\hline Variant 5 & $\begin{array}{l}\text { Standard treatment is applied } \\
\text { Pre-stabilization of the mechanically damaged objects } \\
\text { If applicable, protection against mechanical forces during } \\
\text { bath treatment }\end{array}$ & $\begin{array}{l}\text { Washing after CNF application } \longrightarrow \text { does washing out free iron ions entail an } \\
\text { increased risk of migration? } \\
\text { Fibrillated nanocellulose may be partially washed out }\end{array}$ \\
\hline
\end{tabular}



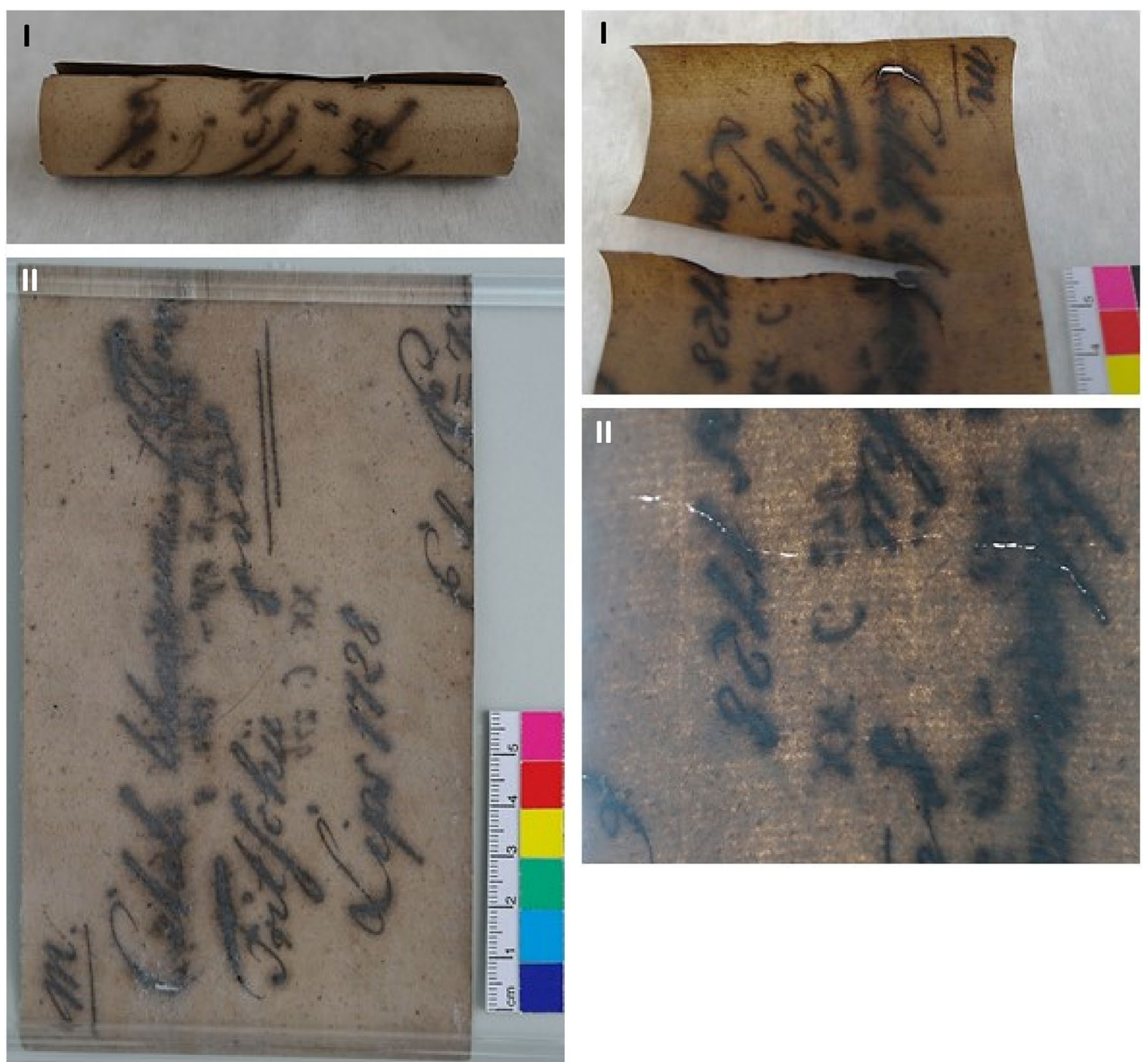

Fig. 2 Variant 5 -CNF B. Sample of bad condition before (I) and after (II) mechanical stabilization by CNF and the chemical phytate treatment. By applying CNF before the chemical treatment, the large fracture and the smaller cracks and breakouts were (pre-)stabilized. No further mechanical damage occurred during the treatment. Rather than that, the good stabilization performance of the CNF is clearly visible at the large fracture

fibrillar network at the papers' surface (cf. Fig. 8). The overall optical impression is obviously related to the amount of nanofibrillated cellulose applied [36]. The handwriting was only slightly affected by the presence of nanofibres since the formed networks adhered tightly and homogeneously to the surface. The treated areas were hardly visible, or not discernible at all. The main advantage is that there are no perceptible fibres or fibre network structures-as in the case of treatment with Japanese paper-at the surface [45]. This is particularly advantageous for papers which are densely written with iron-gall ink.

After accelerated degradation, optical changes occurred that were well perceptible with the human eye.
The color differences of the aged samples in comparison to the unaged ones were quantified by CIELab analysis. The strongest yellowing occurred in the case of the untreated references as expected. The phytate-treated reference sample served as direct comparison to the treatments with phytate/nanocellulose combination (cf. Fig. 4). The CIELab data agreed well with the observed stabilization of the cellulose by the phytate treatment: also the overall yellowing was strongly reduced and the optical integrity of the sample was preserved. The presence of nanocellulose did not interfere with this stabilization. The samples-albeit historic materials covered with iron-gall ink in tight handwriting, thus being of inherent optical inhomogeneity-yielded CIELab data comparable 

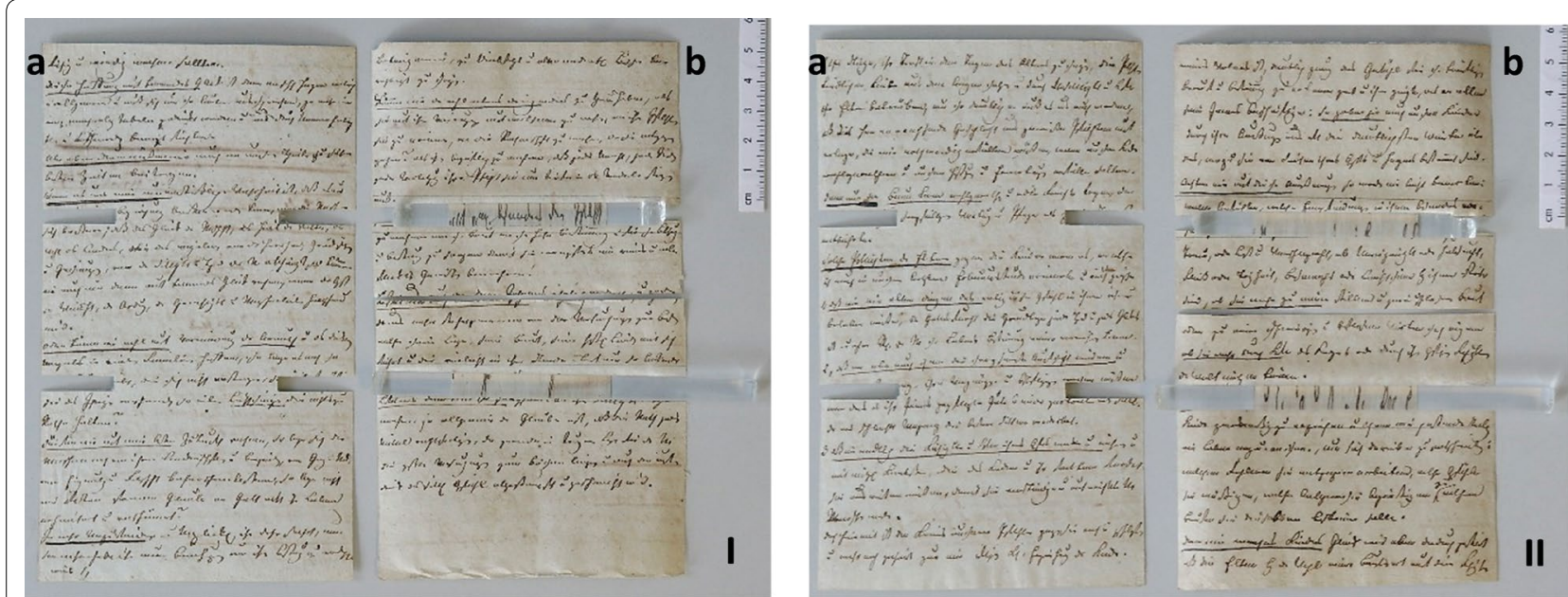

Fig. 3 Treated samples of fair condition (a unaged, $\mathbf{b}$ aged). Left picture (I): Variant 4, CNF B; right picture (II): Variant 5, CNF B. The shadow on the right sample paper was caused by its curvature

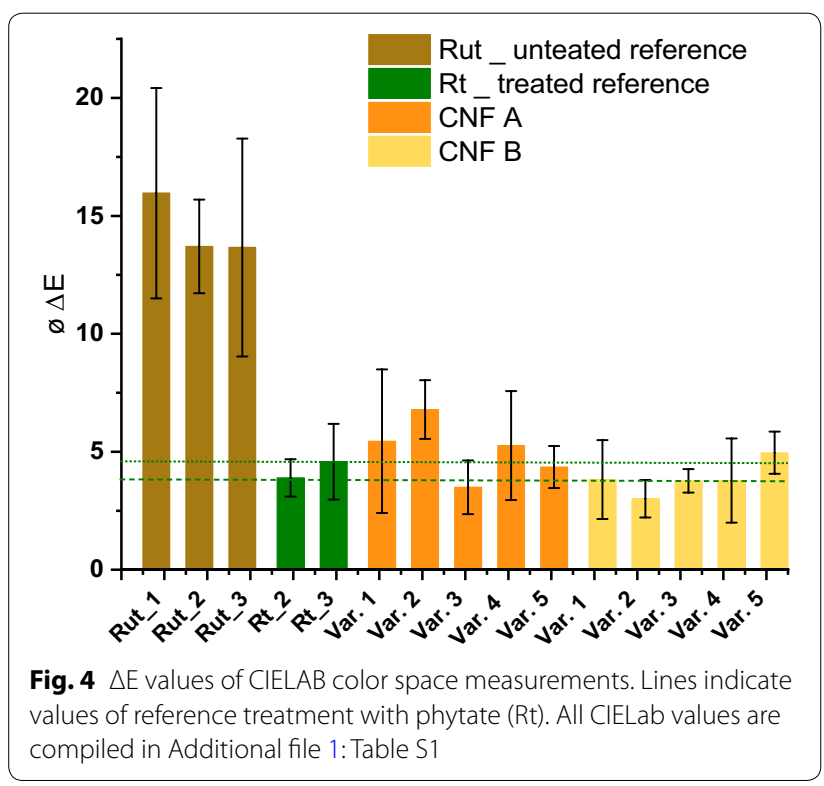

to the phytate-treated reference. No distinct differences were visible between the different treatment variants, and neither did CIElab analysis reveal any significant differences between the two nanocelluloses CNF A and CNF B are visible (cf. Fig. 4).

This result is supported by the data of the whiteness analysis. It was evident that the CNF material alone has a rather low tendency to yellowing during accelerated degradation over a longer period of time ( 40 days; see Additional file 1: Fig. S3).

The following observation was noticeable throughout the samples: The more browned the paper or the darker the ink, the more clearly and quickly the CNF layers that formed on the paper surface appeared as light or whitish veils on the surface (e.g. cf. Additional file 1: Figure S1). Especially a comparison of the samples of fair condition with the poor and bad condition made this observation obvious. This aspect was more pronounced when CNF was applied with the brush.

The CNF networks that formed on the paper surface had only a very small influence on the haptic properties of the samples. The flexibility of the papers was retained, and no tension was created. In addition, the paper structure, i.e. the fibre network with its interstitial spaces, remained clearly visible in the SEM analysis images (Figs. 6, 8). It can be concluded that the CNF layer has only a slight influence on the appearance and haptics of the overall sample material.

The sample surface in the ink-covered and ink-free paper areas of the untreated samples generally showed contact angles larger than $90^{\circ}$. Hydrophobic surface properties prevailed over the entire surface and not just in areas covered with ink. Unaged and aged samples showed no significant differences (Fig. 5): On average, the contact angles before and after aging were similar for inkcovered and ink-free areas.

\section{Microscopy-SEM-EDX}

The microscopic analysis of individual samples produced interesting outcomes for the different treatment procedures. A sample of variant 2 (combined $\mathrm{Ca}\left(\mathrm{HCO}_{3}\right)_{2}$ - $\mathrm{CNF}$ application) showed $\mathrm{CaCO}_{3}$ particles and agglomerates on the paper fibre matrix (cf. Fig. 6), immobilized in the 

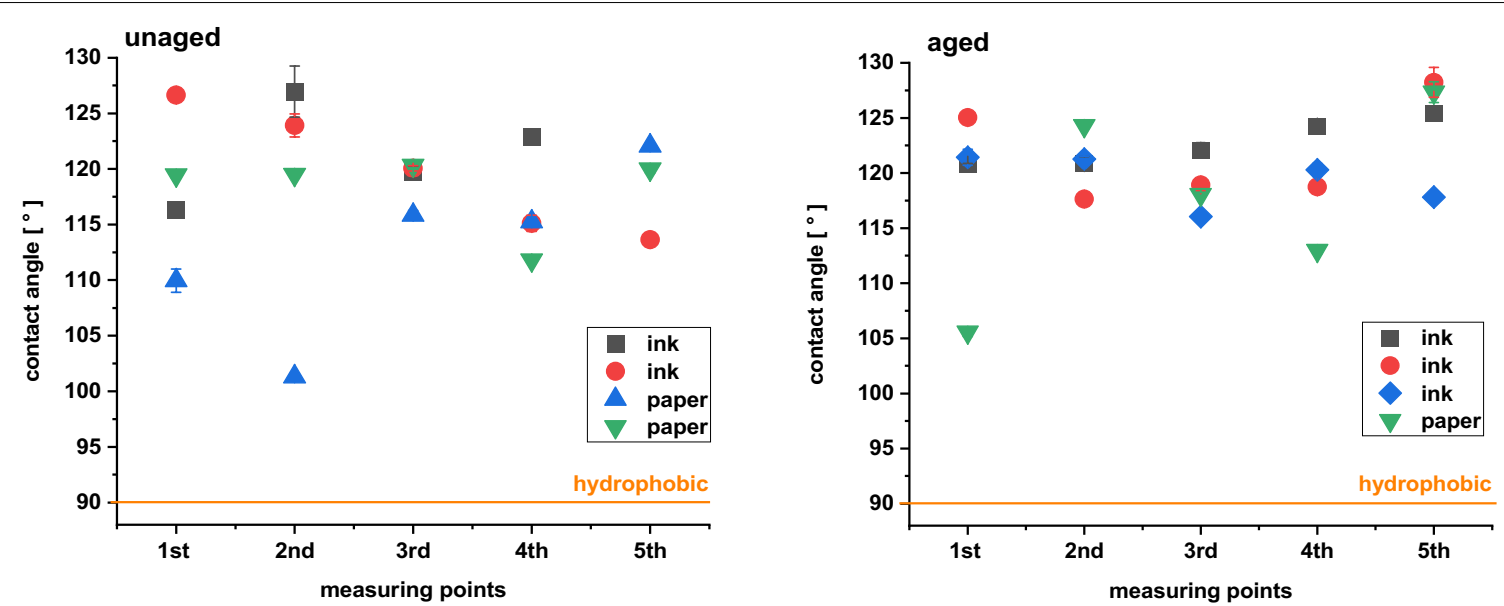

Fig. 5 Contact angle analysis for untreated samples: unaged (left) and aged (right). The different symbols represent different surface areas

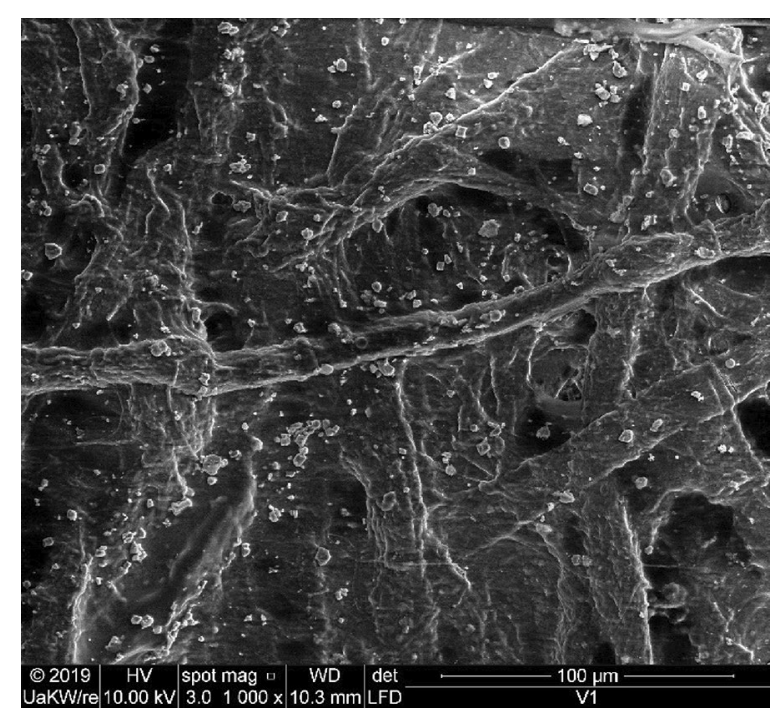

Fig. 6 SEM image of the paper treated with CNF B (variant 2). The CNF layer on the paper fibres as well as inorganic particles and agglomerates on the fibres are visible

CNF network because the CNF was suspended in the calcium hydrogencarbonate solution prior to application.

Even with variant 5 (initial CNF application), some small, white particles and crystals were visible on the fibrillar network surface. They were homogeneously distributed and had a size of $100-200 \mathrm{~nm}$. Also some agglomerates had formed. EDX analysis confirmed calcium and phosphorus in the crystals. Due to the early $\mathrm{CNF}$ application, calcium phytate and calcium carbonate deposit directly on the network (cf. Fig. 7). In comparison, variant 4 showed only a few particles because CNF was applied as the last step and the fibre network on the surface formed after the chemical treatment. The few crystals found were probably introduced by entrainment of the fleece in or on the CNF layer (cf. Fig. 7).

It was interesting to note that in all samples the CNF network also formed in and around the ink area, the same way it did on the blank paper (cf. Fig. 8). Taking the contact angle measurements into account, which showed similar surface properties in all areas, it was evident that the network formation was not disturbed by different areas of the surface. Under the condition of prolonged conditioning and gentle pre-wetting with decreasing alcohol content, the formation of a closed, stabilizing CNF layer was supported despite a hydrophobic surface. Most probably, van der Waals interactions played a decisive role in the formation and adhesion of the CNF network.

\section{Laser ablation inductively coupled plasma mass spectrometry (LA-ICP-MS)}

One of the main concerns of restorers is the migration of free metal ions during and after treatment of papers containing iron gall ink. Migration is caused by excessive exposure to moisture and lack of complete removal or re-depositing of free metal ions during a bath. Free transition metal ions catalyse cellulose degradation and eventually destroy the paper.

The analysis of the migration of iron ions upon the treatments and during aging was performed with laser ablation inductively coupled plasma mass spectrometry (LA-ICP-MS). LA-ICP-MS reveals the spatial distribution of elements-in this study, iron-on the paper surface. It is a powerful analytical tool to monitor spatial movements of chemical element. In this study, the surface distribution was monitored upon calcium phytate/ calcium hydrogencarbonate treatment [9]. It was important to determine whether the application of CNF at 

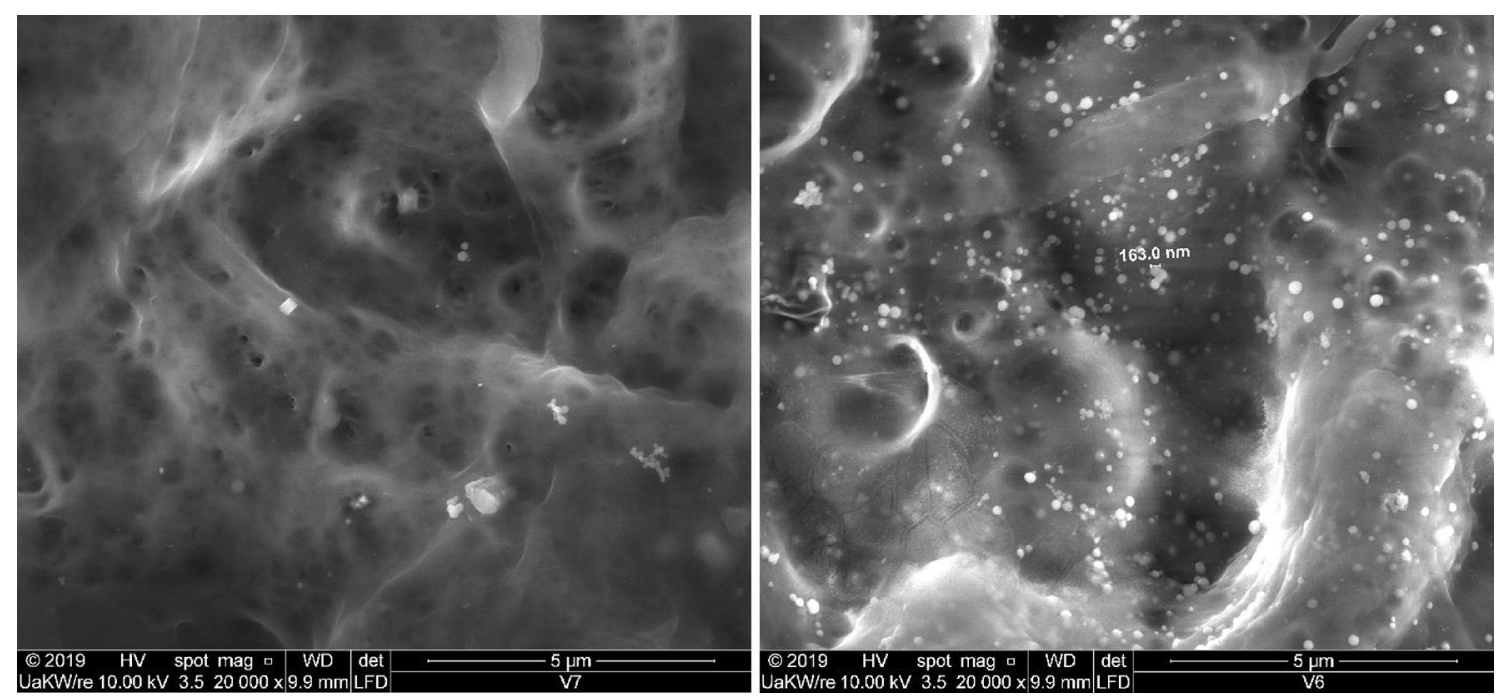

Fig. 7 Comparison of manuscripts treated with CNF B in variant 4 (left) and variant 5 (right). Left: the CNF network was formed in the last step, hence only a few particles were visible at the surface. Right: many particles were deposited onto the CNF network surface, which was formed in the first step of the treatment. The EDX spectra of the small particles showed the presence of calcium and phosphorus (for EDX cf. Additional file 1: Figure S2)

different stages of the treatment process triggered migrations of iron ions before, during, or after the treatment. It was particularly interesting to see whether migration occurred because of the additional CNF step, and whether the position of this step within the treatment sequence (before the chemical treatment or as the final step) had an influence. Untreated and treated references were compared and samples with CNF applied at different sites were investigated.

The evaluation was based on the background signal of the reference samples. If the ${ }^{57} \mathrm{Fe}$ signal was higher than the background signal of $0.7( \pm 0.2)$ relative intensity, it was considered significant, indicating an increased concentration of iron. Directly next to the ink areas, it was checked whether the treatments resulted in washing-out of iron ions. Such an event would have been noticeable by a wider iron distribution next to the original ink area.

The visual comparison of the measurement lines with the measured $\mathrm{Fe}$ intensities showed that there was no leaching of iron ions, neither through the treatment itself nor through the integration of the CNF application. If the untreated references were measured across the ink lines, clear, abrupt increases or decreases in the iron intensity in relation to the ink profiles occurred. Those clear iron profiles corresponding to the ink lines were similarly observed in the treated samples-also with CNF application. There were no wider distributions detected that reached into the paper next to the ink lines, confirming that no water-induced migration of iron ions occurred (cf. Fig. 9).
The evaluation of the samples with the calculated background signal of reference samples $(0.7( \pm 0.2)$ relative intensity) showed some single, narrow iron spike signals. They ranged from 1.6 to 12.9 in relative intensity $\left({ }^{57} \mathrm{Fe} /{ }^{13} \mathrm{C}\right)$ and occurred in the untreated references as well as in the treated samples. Since those peaks were not related to migration phenomena, occurred in all sample papers and were sometimes very intense or even higher than the iron intensity in the ink line, it is reasonable to assume that they originate from iron inclusions paper production, most probably mineral microparticles that contain iron oxide.

\section{Cellulose integrity after aging}

Besides the optical and haptical properties of the paper, the chemical cellulose integrity, as a molecular parameter, is very important for any novel conservation treatment suggested. The cellulose analysis performed in this study aimed at demonstrating that the extra stabilization step with CNF did not compromise the effect of the phytate treatment, and at identifying the best stabilization variant for the implementation of nanofibrillated cellulose among the tested ones.

Size exclusion chromatography (SEC) is the method of choice to analyse the molecular weight distribution of celluloses and their integrity upon a treatment. To evaluate the effectiveness of the treatment variants, the number of cellulose chain scissions after accelerated degradation was calculated and compared, which allowed data evaluation independent of the initial molecular 


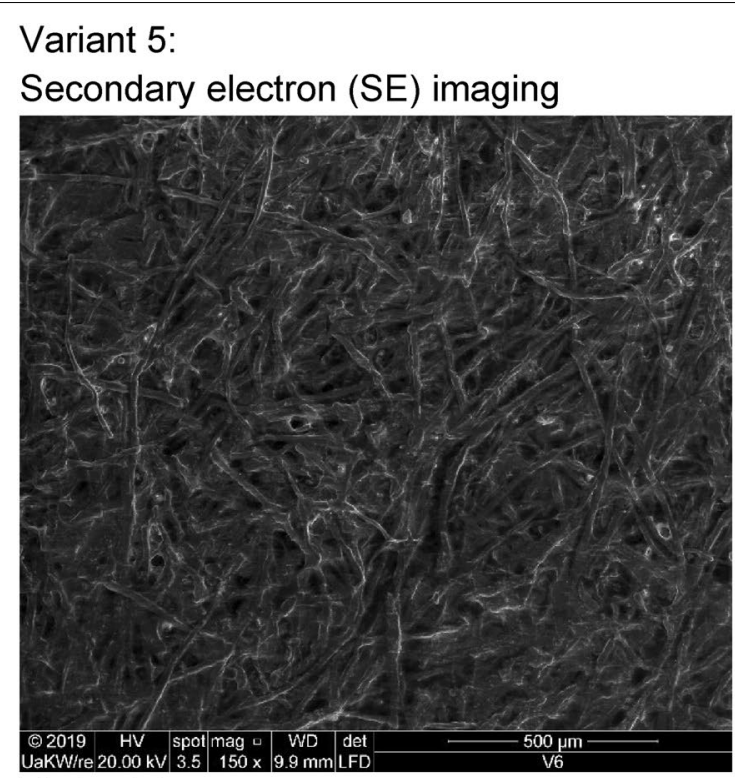

\section{Back-scattered electron (BSE) imaging}

Variant 4:

Secondary electron (SE) imaging
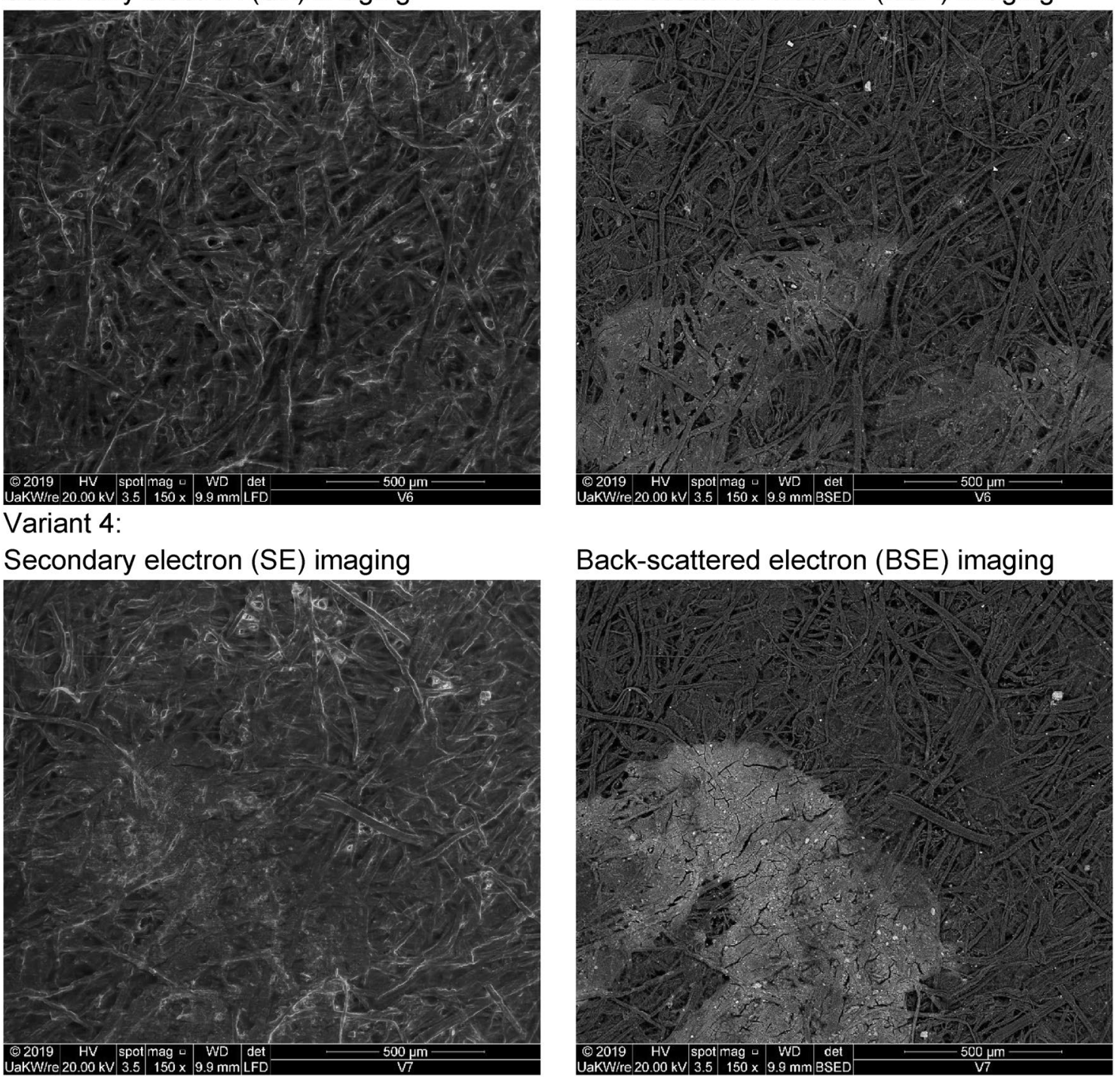

Back-scattered electron (BSE) imaging

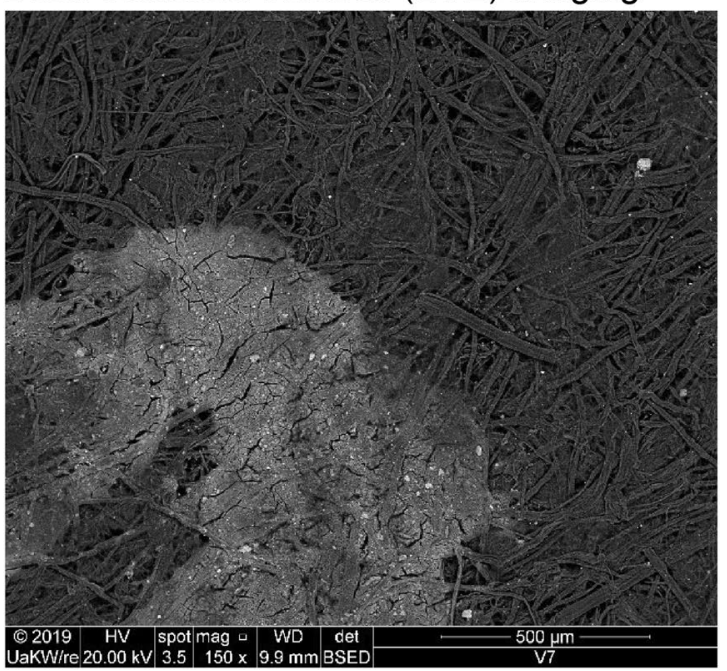

Fig. 8 Treated paper areas - blank and described paper areas in secondary electron mode and back-scattered electron (BSE) mode. In both variant 5 and variant 4, the CNF network was formed homogeneously on blank and described paper surface areas. SE images (left) showed the paper and network surface. In BSE mode, the ink and the blank areas are clearly distinguished

weight. This was especially relevant when working with historical rag papers which always have slightly different molar masses in a sheet due to inherent sample inhomogeneities. The calcium phytate/calcium hydrogencarbonate treatments alone have been shown to be very effective at lowering the number of chain scissions after accelerated degradation [44].

\section{Reference samples}

The untreated reference papers showed the degradation of cellulose during accelerated degradation without any treatment or additives. The clear degradation was evident from a significant reduction in molar mass and an increase of carbonyl groups (cf. Fig. 10).

Hydrolytic processes in all three papers caused the cleavage of glycosidic bonds, thus reducing the DP and at the same time forming 'new' reducing end groups. Similarly, new carbonyl groups were introduced along the cellulose chains by oxidation. The three reference papers 

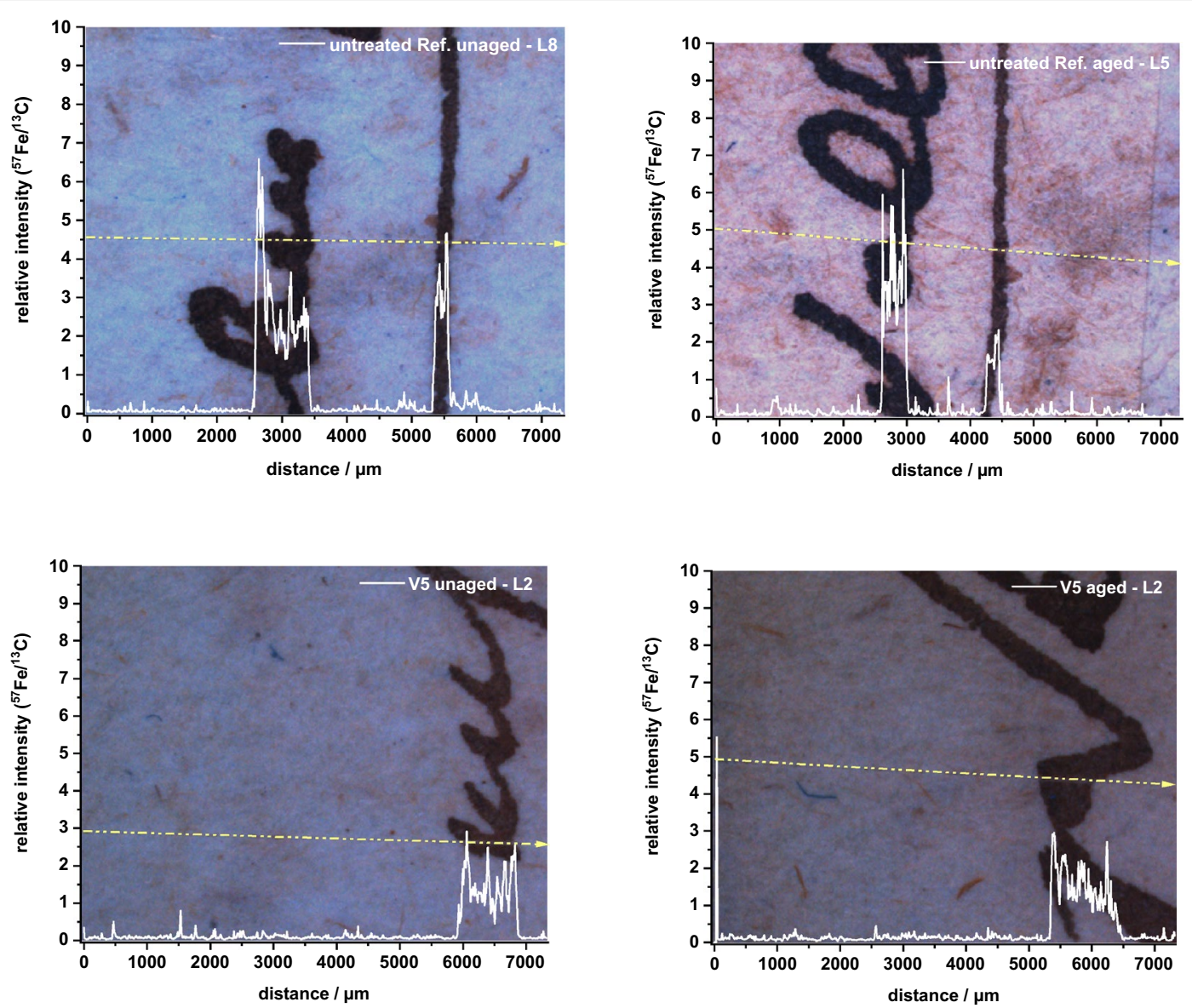

Fig. 9 LA-ICP-MS results of untreated reference (above) and sample treated with variant 5 (below). Unaged samples (left) and aged samples (right). Lines indicate the trace of the laser ablation

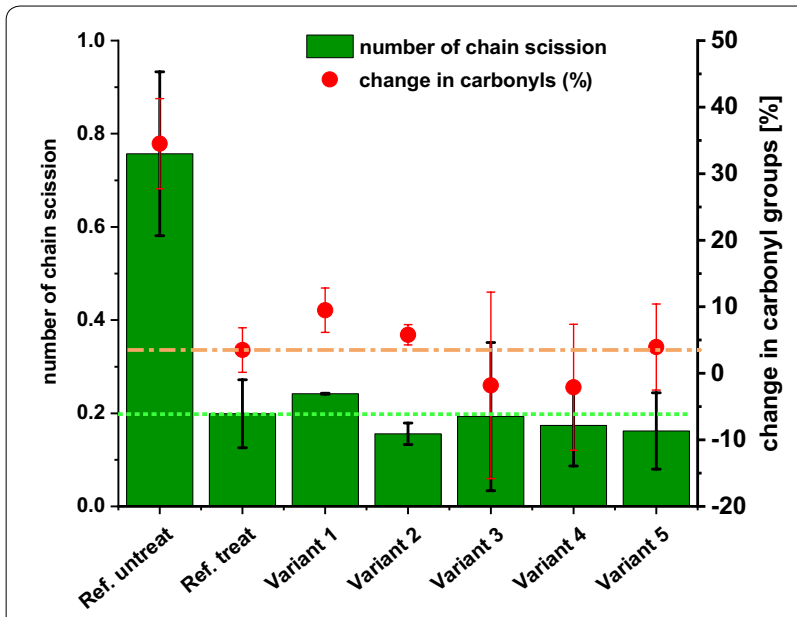

Fig. 10 Average number of chain scissions and carbonyl group contents (\%) of reference samples and treatment variants of both CNF types after accelerated degradation. Lines indicate average numbers from the reference treatment with phytate only showed chain scissions of around 0.76 and an increase of carbonyl groups by an average of $34.5 \%$ after aging.

The treated reference papers corroborated the beneficial effect of a regular calcium phytate/calcium hydrogencarbonate treatment (without CNF treatment). Both hydrolysis and oxidation were slowed down significantly, as expected (cf. Fig. 10). The chemical treatment reduced the number of chain scissions from an average of 0.76 to 0.20 , and the formation of carbonyl groups was reduced from $34.5 \%$ to $3.5 \%$.

Based on the analysis of carbonyl groups and molar mass, the degradation during aging was mainly induced by hydrolysis. The degradation processes have not been completely stopped by the treatment, but oxidation was considerably slowed down. All in all, the results convincingly proved the effectivity of a calcium phytate/ calcium hydrogencarbonate treatment in decreasing both hydrolytic and oxidative processes caused by iron gall ink. This is in good agreement with the results of previous investigations $[8,9]$. 

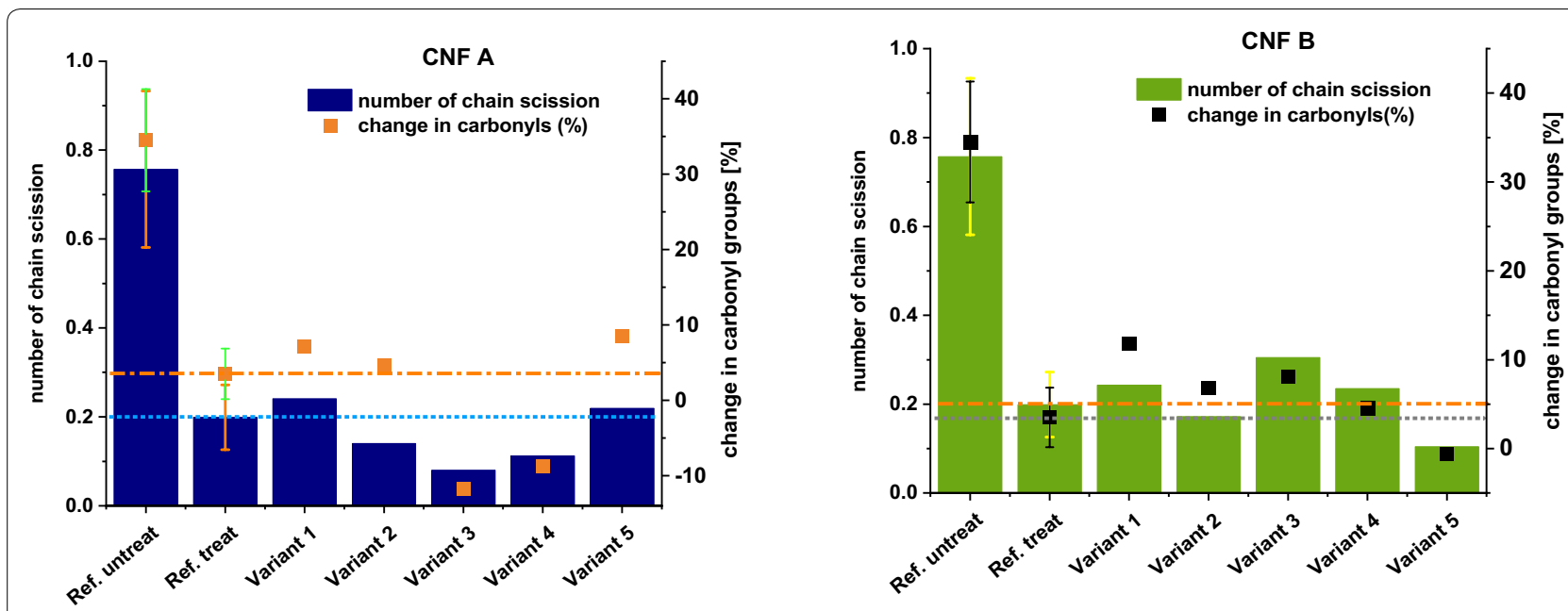

Fig. 11 Comparison of different NFCs, left CNF A, right: CNF B: Number of chain scission and carbonyl group contents (\%) after accelerated degradation. Lines indicate average numbers from the reference phytate treatment

With regard to the treatments with CNF, it was evident that no increased cellulose degradation occurred for four out of five treatment variants (cf. Fig. 10).

Only for variant 1 the number of chain scissions was slightly higher, at an average of 0.24 compared to the treated reference ( 0.20 chain scissions). The formation of carbonyl groups was also slightly increased in this case: an average increase of $9.5 \%$ compared to $3.5 \%$ for the treated reference. The lower effectiveness of variant 1 was due to the significantly reduced treatment time (no complexing bath). By sole application of the calcium phytateCNF suspension not all iron ions could be effectively masked. This resulted in a less stable material after aging. Thus, the shortened treatment time clearly had a negative overall effect.

In contrast, the samples of variant 2-also with a shorter treatment time (deacidification bath), but with combined application of calcium hydrogencarbonate and $\mathrm{CNF}$-showed an average decrease of chain scissions to 0.16 , thus indicating a very effective treatment. The small decrease of molecular weight and the smaller formation of reduced end groups indicated beneficial neutralizing effect of calcium carbonate during accelerated degradation, which must have been retained by the fibril network and thus remained available as an alkaline reserve.

Treatment variants 3 to 5 all showed a lower average of chain scissions and no increased formation of carbonyl groups (cf. Fig. 10) relative to the reference. For one of the two treatment batches, the values were significantly below the treated reference-variants 3 and 4 for CNF A (cf. Fig. 11 left) and Variant 5 for CNF B (cf. Fig. 11 right). Thus, the treatments generally had a strongly protective effect on the cellulose. On average, the stabilization data of the standard protocol and the variants were not significantly different. Thus, it can be stated that with regard to cellulose protection all the variants behaved like the regular phytate treatment. Therefore, the differences seen with the two CNF types were most likely not due to the CNF material itself or a lower effectiveness of the treatment process, but rather due to inhomogeneities of the historical rag papers. Accordingly, it can be concluded that the integration of CNF in the gelatine sizing process or as a mechanical stabilization step after or before the treatment process does not at all impair the clear stabilization effect of the phytate treatment.

The treatment effectiveness was fully maintained, also in the case of incorporation of nanofibrillated cellulose. The surface layer of CNF and gelatine was not adhesive or sticky to the touch. Presumably, the concentration of gelatine (2\%) was sufficiently low to avoid such negative effects. Experiments in which the gelatine system is investigated in more detail, e.g. at increased ambient humidity, were outside the scope of this study, although they would be important for a final assessment.

With Variants 4 and 5, the treatment had the expected positive effect on the integrity of the cellulose. The hydrolytic and oxidative degradation processes were effectively reduced. At the same time, papers weakened or damaged by corroded iron gall ink were mechanically stabilized. Particularly in variant 5 , the pre-stabilization of strongly damaged papers by CNF (as step 2) was very attractive, as it protected the papers from mechanical forces during subsequent bath treatments and reduced the risk of new damage. Also in the presence of CNF, the complexing and deacidifying reagents acted as desired, and the effectiveness of the treatment 
baths was not lowered. The calcium phytate/calcium hydrogencarbonate medium stabilized the CNF network: a loss of CNF during the subsequent bath applications was basically not observed. As the samples were not washed before CNF application, an increased risk of migration of free iron ions might have been suspected, but the LA-ICP-MS measurements (see above) demonstrated that this was not the case.

\section{Conclusion}

Calcium phytate/calcium hydrogencarbonate treatment for the chemical stabilization of iron gall inks, on the one hand, and the application of nanofibrillated celluloses as mechanical stabilization iron gall ink paper, on the other hand, can be effectively combined. The benefit of the chemical treatment was not impaired while, moreover, significant additional mechanical stabilization was gained. The CNF acts as a stabilizing network, has little to no optical interference and does not change the haptic properties of the manuscripts. In addition, the material acted as a stabilizing protective layer during accelerated degradation. It is not diminished or negatively affected by any subsequent aqueous steps. Both tested CNFs worked equally well with regard to application and stabilization effect.

From a conservation point of view, variants in which the CNF is applied as a pure suspension at the end (variant 4) and at the beginning (variant 5) of the treatment are particularly promising, as they have great conservation and restoration potential to stabilize more severely damaged manuscripts during the phytate treatment. Above all, the effective pre-stabilization of objects with severe mechanical damage demonstrated the viability of a treatment option that has not been available so far.

To transfer the combined method into general practical use, further tests are necessary, especially with more objects in poor and bad condition. Also application of fibrillated nanocellulose can be further optimized to make sure that always a uniform, stabilizing, yet optically unobtrusive effect is obtained. Furthermore, the opportunity a local, spatially resolved application of CNF on manuscripts is of high relevance from the perspective of conservation practice. The most suitable variants from the practical point of view (Gelatine-CNF application, CNF application as last step and CNF application as first step) are to be further elaborated. In addition, criteria for the respective applications variants should be developed as recommendations. The transfer of the variants into practice and the optimization of the treatment processes must be supported by concomitant analytical investigations of cellulose (SEC and LA-ICP-MS-measurements) to ensure quality control and process effectiveness.

\section{Supplementary information}

Supplementary information accompanies this paper at https://doi. org/10.1186/s40494-020-00428-6.

Additional file 1: Figure S1. Variant 5-CNF A. Sample of condition rating 3 before and after the chemical phytate treatment and mechanical stabilization by CNF. Figure S2. EDX spectra of crystals on manuscript, which was treated with CNF B in Variant 5. Figure S3. ISO brightness measurement of CNF films. Table S1. Mean values of $\Delta L^{*}, \Delta a^{*}, \Delta b^{*}, \Delta E$ from the CIELAB measurement.

\section{Abbreviations}

CCOA: Carbazole-9-Carbonyl-Oxy-Amine; CNF: Cellulose nanofibers/cellulose nanofibrils/nanofibrillated cellulose; DP: Degree of polymerization; LA-ICP-MS: Laser ablation inductively coupled plasma mass spectrometry; LOD: Limit of detection; Mw: Molecular weight; PE: Polyethylene; SEC: Size exclusion chromatography; SEM-EDX: Scanning electron microscope with energy dispersive X-Ray analysis.

\section{Acknowledgements}

We thank Rudolf Erlach, University of Applied Arts Vienna, Institute of Art and Technology, Natural Sciences in Conservation, for his support in the microscopic analyses, Prof. em. Dr. Gerhard Banik for interesting and helpful discussions and comments, and Dr. Sonja Schiehser, Dickson Daniel Kofi Owusu and Florian Bausch for the practical support in the laboratory. L.V. would like to thank Klassik Stiftung Weimar and the doctoral school ABC\&M for financial support. The financial support of the Austrian Biorefinery Center Tulln (ABCT) is also gratefully acknowledged.

\section{Authors' contributions}

LV designed/conducted the practical and scientific work, evaluated/interpreted the data and wrote the major parts of the manuscript. AP designed the scientific part and coordinated the study, evaluated/interpreted data and wrote the parts of the manuscript. TP performed the LA-ICP-MS measurements, evaluated data. All authors read and approved the final manuscript.

\section{Funding}

The project is funded by University of Natural Resources and Life Sciences (BOKU), the Klassik Stiftung Weimar-Herzogin Anna Amalia Bibliothek, and the BOKU doctoral school ABC\&M ("Advanced biorefineries-chemistry and materials").

\section{Availability of data and materials}

The datasets used and/or analysed during the current study are available from the corresponding author on request. Additional file 1 is also available.

\section{Competing interests}

The authors declare that they have no competing interests.

\section{Author details}

${ }^{1}$ Department of Conservation and Special Collections, Herzogin Anna Amalia Bibliothek - Klassik Stiftung Weimar, Platz der Demokratie 1, 99423 Weimar, Germany. ${ }^{2}$ Chair of General and Analytical Chemistry, Montanuniversität Leoben, Franz Josef-Straße 18, 8700 Leoben, Austria. ${ }^{3}$ Department of Chemistry, Institute of Chemistry of Renewables and Institute of Wood Technology and Renewable Materials, University of Natural Resources and Life Sciences (BOKU), Konrad-Lorenz-Strasse 24, 3430 Tulln, Austria.

Received: 6 May 2020 Accepted: 5 August 2020

Published online: 26 August 2020

\section{References}

1. Kolar J, Strlič M. Iron gall inks: on manufacture characterisation, degradation and stabilisation. Ljubljana: National and University Library; 2006.

2. Reißland B. Neue Restaurierungsmethoden für Tintenfraß auf Papier mit wäßrigen Phytatlösungen-Möglichkeiten und Grenzen. In: Banik G, Weber $\mathrm{H}$, editors. Tintenfraßschäden und ihre Behandlung. Stuttgart: 
Kohlhammer; 1999. p. 113-220 (Werkhefte der Staatlichen Archivverwaltung Baden-Württemberg).

3. Wunderlich C-H. Geschichte und Chemie der Eisengallustinte: rezepte. Reaktionen und Schadwirkungen. Restauro. 1994;6:414-21.

4. Ponce A, Brostoff LB, Gibbons SK, Zavalij P, Viragh C, Hooper J, et al. Elucidation of the Fe(III) gallate structure in historical iron gall ink. Anal Chem. 2016;88(10):5152-8.

5. Díaz Hidalgo RJ, Córdoba R, Nabais P, Silva V, Melo MJ, Pina F, et al. New insights into iron-gall inks through the use of historically accurate reconstructions. Herit Sci. 2018;6(1):586.

6. Liu Y, Kralj Cigić I, Strlič M. Kinetics of accelerated degradation of historic iron gall ink-containing paper. Polym Degrad Stab. 2017;142:255-62.

7. Šelih VS, Strlič M, Kolar J, Pihlar B. The role of transition metals in oxidative degradation of cellulose. Polym Degrad Stab. 2007;92(8):1476-81.

8. Potthast A, Henniges U, Banik G. Iron gall ink-induced corrosion of cellulose: aging, degradation and stabilization: Part 1: model paper studies. Cellulose. 2008;15(6):849-59.

9. Henniges U, Reibke R, Banik G, Huhsmann E, Hähner U, Prohaska T, et al. Iron gall ink-induced corrosion of cellulose: aging, dagradation and stabilization: Part 2: application on historic sample material. Cellulose. 2008;15(6):861-70.

10. Neevel JG. Phytate: a potential conservation agent for the treatment of ink corrosion caused by iron gall inks. Restaurator Int J Preserv Library Arch Mater. 1995;16(3):143-60.

11. Neevel JG. Phytate als chemische Inhibitorenvon Tintenfraß auf Papier. In: Banik G, Weber H, editors. Tintenfraßschäden und ihre Behandlung. Stuttgart: Kohlhammer; 1999. p. 87-111 (Werkhefte der Staatlichen Archivverwaltung Baden-Württemberg).

12. Banik G. Phänomene und Ursachen von Tintenfraß auf Papier-eine Einführung. In: Banik G, Weber H, editors. Tintenfraßschäden und ihre Behandlung. Stuttgart: Kohlhammer; 1999. p. 13-24 (Werkhefte der Staatlichen Archivverwaltung Baden-Württemberg).

13. Rouchon-Quillet $V$, Remazeilles C, Bernard J, Wattiaux A, Fournes L. The impact of gallic acid on iron gall ink corrosion. Appl Phys A. 2004;79(2):389-92.

14. Reissland B, Hofenk de Graaff, Judith. Condition rating for paper objects with iron-gall ink. In: Instituut Collectie Nederland, editor. Condition rating for paper objects with iron-gall ink. Amsterdam; 2001. p. 1-4.

15. Haberditzl A. Tintenfraßbehandlung- Umsetzung von Theorien in die Praxis der Werkstätten. In: Banik G, Weber H, editors. Tintenfraßschäden und ihre Behandlung. Stuttgart: Kohlhammer; 1999 (Werkhefte der Staatlichen Archivverwaltung Baden-Württemberg).

16. Dekle C, Haude ME. Iron-gall Ink treatment at the library of congress: old manuscripts-new tools. Book Paper Group Annual. 2008;27:15-26.

17. Albro S, Biggs JL, Dekle C, Haude ME, Karnes C, Khan Y. Developing guidelines for iron-gall ink treatment at the library of congress. Book Paper Group Annual. 2008;27:129-65.

18. Sistach M, Marin E, Garcia J. Evaluation of alkaline compounds used for deacidification and simultaneous lining of extremely degraded manuscripts. Restaurator Int J Preserv Library Arch Mater. 2017;38(3):249-72.

19. Henniges U, Potthast A. Phytate treatment of metallo-gallate inks: Investigation of its effectiveness on model and historic paper samples. Restaurator Int J Preserv Library Arch Mater. 2008;29(4):219-34.

20. Guild S, Tse S, Trojan-Bedynski M. Technical note in treatment options for iron gall ink on paper with a focus on calcium phytate. J Canadian Assoc Conserv (JCAC). 2012;37:17-21.

21. Huhsmann E, Hähner U. Work standard for the treatment of 18th- and 19th-century iron gall ink documents with calcium phytate and calcium hydrogen carbonate. Restaurator 2008; 29(4):274-319. http://www.degru yter.com/downloadpdf/j/rest.2008.29.issue-4/rest.2008.020/rest.2008.020. $\mathrm{xml}$.

22. Huhsmann E, Hähner U. Technical note: application of the non-woven viscose fabric paraprint OL 60 for float screen washing of documents damaged by iron gall ink Corrosion. Restaurator. 2007;28(2):131.

23. Pataki-Hundt A, Walter C. Comparison of lightweight Japanese tissues for overall stabilization of documents damaged by iron gall ink corrosion and an alternative to silk screen frames. Restaurator Int J Preserv Library Arch Mater. 2018;39(2):109-27.

24. Rouchon V, Desroches M, Duplat V, Letouzey M, Stordiau-Pallot J. Methods of aqueous treatments: the last resort for badly damaged iron gall ink manuscripts. J Paper Conserv. 2012;13(3):7-13.
25. Titus S, Schneller R, Huhsmann E, Hähner U, Banik G. Stabilising local areas of loss in iron gall ink copy documents from the Savigny estate. Restaurator Int J Preserv Library Arch Mater. 2009;30(1-2):16-50.

26. Jacobi E, Reissland B, Luu CPT, van Velzen B, Ligterink F. Rendering the invisible visible: preventing solvent-induced migration during local repairs on iron gall ink. J Paper Conserv. 2011;12(2):25-34.

27. Pataki A. Remoistenable tissue preparation and its practical aspects, Restaurator Int J Preserv Library Arch Mater. 2009;30(1-2):51-69.

28. Martin A, Rouchon V, Aubry T, Cauliez N, Desroches M, Margez M. Local strenghtening of mould-damaged manuscripts: a case study on logbooks of early french expeditions in Louisiana (1684-1722). J Paper Conserv. 2011;12(1):21-8.

29. Desroches M, Duplat V, Rouchon V. Instructables: an aqueous treatment for highly damaged manuscripts: minimising the risk of mechanical damage. J Paper Conserv. 2012;13(3):36-7.

30. Bridarolli A, Odlyha M, Nechyporchuk O, Holmberg K, Ruiz-Recasens C, Bordes R, et al. Evaluation of the adhesion and performance of natural consolidants for cotton canvas conservation. ACS Appl Mater Interfaces. 2018;10(39):33652-61.

31. Nechyporchuk O, Kolman K, Bridarolli A, Odlyha M, Bozec L, Oriola M, et al. On the potential of using nanocellulose for consolidation of painting canvases. Carbohydr Polym. 2018;194:161-9.

32. Dreyfuss-Deseigne R. Nanocellulose films in art conservation: a new and promising mending material for translucent paper objects. J Paper Conserv. 2017;18(1):18-29.

33. Dreyfuss-Deseigne R. Instructables: a new mending material: nanocellulose film. J Paper Conserv. 2017;18(1):36-7.

34. Pereira FV. Nanocellulose-based composites for conservation and restoration of cultural heritage of paper: Comparative studies between traditional and innovative methods. In: TAPPI international conference on nanotechnology for renewable materials; 14th-16th 2016. p. 348-65.

35. Okayama T, Kadoya C, Kose R, Seki M, Sonod N. A new technique for strengthening degraded paper: application of cellulose nanofiber coating on a paper surface. In: Tagungsband zu XIIIth IADA Congress. Berlin: Laserline; 2015. p. 74.

36. Völkel L, Ahn K, Hähner U, Gindl-Altmutter W, Potthast A. Nano meets the sheet: adhesive-free application of nanocellulosic suspensions in paper conservation. Herit Sci. 2017:5(23):1-17.

37. Kontturi E, Meriluoto A, Penttilä PA, Baccile N, Malho J-M, Potthast A, et al. Degradation and crystallization of cellulose in hydrogen chloride vapor for high-yield isolation of cellulose nanocrystals. Angew Chem Int Ed Engl. 2016;55(46):14455-8.

38. TAPPI. Accelerated temperatur aging of printing and writing paper by dry oven exposure apparatus; 2003.

39. SawoszczukT, Barański A, Łagan JM, Łojewski T, Zięba K. On the use of ASTM closed vessel tests in accelerated ageing research. J Cultural Herit. 2008;9(4):401-11.

40. DIN-Normenausschuss Farbe. Colorimetry—part 4: CIE $1976 L^{*} a^{*} b^{*}$ colour space: Beuth; 2020 2020-03.

41. Potthast A, Röhrling J, Rosenau T, Borgards A, Sixta H, Kosma P. A novel method for the determination of carbonyl groups in cellulosics by fluorescence labeling: 3. Monitoring oxidative processes. Biomacromolecules. 2003:4(3):743-9.

42. Röhrling J, Potthast A, Rosenau T, Lange T, Borgards A, Sixta H, et al. A novel method for the determination of carbonyl groups in cellulosics by fluorescence labeling: 2. Validation and applications. Biomacromolecules. 2002;3(5):969-75.

43. Röhrling J, Potthast A, Rosenau T, Lange T, Ebner G, Sixta H, et al. A novel method for the determination of carbonyl groups in cellulosics by fluorescence labeling: 1. Method development. Biomacromolecules. 2002;3(5):959-68.

44. Potthast A, Ahn K. Critical evaluation of approaches toward mass deacidification of paper by dispersed particles. Cellulose. 2017;24(1):323-32.

45. Santos SM, Carbajo JM, Gómez N, Quintana E, Ladero M, Sánchez A, et al. Use of bacterial cellulose in degraded paper restoration: Part II: application on real samples. J Mater Sci. 2016;51(3):1553-61.

\section{Publisher's Note}

Springer Nature remains neutral with regard to jurisdictional claims in published maps and institutional affiliations. 